autosomal recessive form of RTA, but had strong vertical family history of deafness; the third child had normal hearing.

No abnormalities in total CA activity, isoenzyme distribution, or in electrophoretic mobility could be demonstrated in our three patients with RTA. This may be due to differences in methodology, genetic heterogeneity, or the appearance of the two findings may have been fortuitous. Although we used a different method for demonstrating $\mathrm{CA} B$ activity, no abnormality of CA B could be shown.

The finding of almost complete absence of CA B in the red blood cells of patients with thyrotoxicosis (15) and the demonstration that $\mathrm{CA}$ in rat renal cortex can be inhibited by parathyroid hormone (1) is further evidence that many different factors can influence $\mathrm{CA}$ activity. Therefore, a reduction in CA B activity in the red blood cells of a patient with RTA may not be the cause of the RTA but may be related to other factors, for example, secondary hyperparathyroidism which occurs in some patients with RTA (9).

\section{CONCLUSION}

Red blood cell carbonic anhydrase activity and the two isoenzymes, B and C, of carbonic anhydrase were normal in three children with distal renal tubular acidosis; two of these patients were deaf. Therefore, although defective red blood cell carbonic anhydrase B activity has been demonstrated previously in a child with renal tubular acidosis and deafness, this finding cannot be demonstrated in every patient with these two associated abnormalities.

\section{REFERENCES AND NOTES}

1. Beck, N., Kim, K. S., Wolak, M., Davis, B. B., and Donald, D. H.: Inhibition of carbonic anhydrase by parathyroid hormone and cyclic AMP in rat renal cortex in vitro. J. Clin. Invest., 55: 149 (1975).

2. Carter, M. J.: Carbonic anhydrase: Isoenzymes, properties, distribution, and functional significance. Biol. Rev., 47: 465 (1972).
3. Davis, B. J.: Disc electrophoresis. II. Methods and application to human serum proteins. Ann. N. Y. Acad. Sci., 121: 404 (1966).

4. Donckerwolcke, R. A., van Biervliet, J. P., Koorevaar, G., Kuitjen, R. H., and van Stekelenburg, G. J.: The syndrome of renal tubular acidosis with nerve deafness. Acta Paediat. Scand., 65: 100 (1976).

5. Donckerwolcke, R. A., van Stekelenburg, G. J., and Tiddens, H. A.: A case of bicarbonate-losing renal tubular acidosis with defective carbonanhydrase activity. Arch. Dis. Childhood, 45: 769 (1970).

6. Funakoshi, S., and Deutsch, H. F.: Human carbonic anhydrases. VI. Levels of isoenzymes in old and young erythrocytes and in various tissues. J. Biol. Chem., 246: 1088 (1971).

7. Halperin, M. L., Goldstein, M. B., Haig, A., Johnson, M. D., and Stinebaugh, B. J.: Studies on the pathogenesis of Type I (distal) renal tubular acidosis as revealed by the urinary $\mathrm{pCO}_{2}$ tensions. J. Clin. Invest., 53: 669 (1974).

8. Hutcheon, R. A., Kaplan, B. S., and Drummo.ıd, K. N.: Distal renal tubular acidosis in children with chronic hydronephrosis. J. Pediat., 89: 372 (1976).

9. Michelis, M. F., Drash, A. L., Linarelli, L. G., De Rubertis, R. F., and Davis, B. B.: Decreased bicarbonate threshold and renal magnesium wasting in a sibship with distal renal tubular acidosis (Evaluation of the pathophysiologic role of parathyroid hormone). Metabolism, 21: 905 (1972).

10. Morris, R. C.: Renal tubular acidosis: Mechanism, classification, implications. N. Engl. J. Med., 281: 1405 (1969).

11. Rector, F. C., Carter, N. W., and Seldin, D. W.: The mechanism of bicarbonate reabsorption in the proximal and distal tubule of the kidney. J. Clin. Invest., 44: 278 (1965)

12. Rickli, E. E., Gazanfer, S. A. S., Gibbons, B. H., and Edsall, J. T.: Carbonic anhydrases from human erythrocytes. J. Biol. Chem., 239: 1065 (1964)

13. Sebastian, A., McSherry, E., and Morris, R. C.: Metabolic acidosis with special reference to the renal acidosis. In: B. M. Brenner and F. C. Rector: The Kidney, pp. 615-660 (W. B. Saunders Co., Philadelphia, 1976).

14. Shapira, E., Ben Yoseph, Y., Eyal, F. G., and Russel, A.: Enzymatically inactive red cell carbonic anhydrase $B$ in a family with renal tubular acidosis. J. Clin. Invest., 53: 59 (1974).

15. Weatherall, D. J., and McIntyre, P. A.: Developmental and acquired variations in erythrocyte carbonic anhydrase isozymes. Brit. J. Haematol., 13: 106 (1967).

16. This research was supported by the Medical Research Council of Canada Grant MA-1579 and a grant from the RVH-MCH Chapter Kidney Foundation of Canada.

17. Requests for reprints should be addressed to: B. S. Kaplan, M.D., Department of Nephrology, Montreal Children's Hospital, 2300 Tupper St., Montreal, Quebec (Canada).

18. Received for publication December 9,1976

19. Accepted for publication March 2, 1977.

\title{
Prednisone Effects on Postnatal Brain Development of Rats Following Maternal Therapy
}

\author{
MARTA C. ROMANO, ${ }^{(23)}$ INÉS A. GIOIA, AND M. VIRGINIA BERNASCONI \\ Instituto de Fisiología, Facultad de Ciencias Médicas, Universidad Nacional de Rosario, Argentina
}

\section{Summary}

16- $\beta$-Metilprednisone was administered in the last week of pregnancy in order to study its effects on postnatal brain development of the litters. Two groups of pregnant inbred rats were used for the experiments. Group I received $1.25 \mathrm{mg} / \mathrm{kg} /$ day 16 $\beta$-metilprednisone. Group II served as untreated controls. The litters were killed either within $24 \mathrm{hr}$ after birth, at 17 days, or at 45 days of age. Treated litters (animals whose mothers received the steroid) had a decreased body weight at 17 days of age. Wet brain weight was decreased in the same group. At 17 and 45 days of life treated rats showed a dry brain weight lower than that of controls. Newborn and 17-day-old rats whose mothers received the steroid showed a decreased content of brain proteins. Total lipids, cholesterol, and phospholipids were reduced in the brain of treated rats at $\mathbf{4 5}$ days of life. Brain phospholipids were also decreased in 17-day-old rats. These results show that 16- $\beta$-metilprednisone administration to pregnant rats produces long lasting changes in brain chemical composition.

\section{Speculation}

The brain lipid deficiencies observed may interfere with the myelination process. Further studies are needed to test whether 
all of these changes are spontaneously reversed and to investigate whether the chemical changes are correlated with brain functional deficits.

Cortisone and its natural and synthetic derivatives are used largely in human therapeutics. Furthermore, corticoids are used as fetal enzymatic pulmonary inductors when a premature delivery is expected. Fetal development can be affected by adverse conditions imposed on the maternal organism. These events frequently result in permanent or transitory disorders of maturational patterns. These disorders are intimately related to the developmental stage during which the subject receives the insult $(1,17)$. Effects of different glucocorticoids on development have been reported by different authors. Sames and Leatham (14) showed that body weight is decreased when the chick embryo is treated with cortisone. Weight inhibition and defects in facial bones, tibia, and exteriorized viscera occur when cortisone is administered during early development of the chick embryo; when the drug is administered at a later stage facial bones are not affected but body weight and osseous development present major disturbances (11). Malformations of limbs and palate are present in mice whose mothers were treated with hidrocortisone acetate in the course of pregnancy $(7)$. Some authors $(15,19)$ reported that human fetal damage was minimal when mothers were treated with corticoids in the course of pregnancy, but they studied children at only birth. Other authors $(12,16)$ reported evidences of serious human damage.

In light of the known metabolic effects of glucocorticoids and the above mentioned developmental changes, the possibility that administration of $16-\beta$-metilprednisone might produce biochemical and structural changes in the nervous system of developing animals warrants consideration.

In the present work, $16-\beta$-metilprednisone was administered to pregnant rats. Some aspects of the chemical development of the brain were studied in the newborn up to the pubertal age.

\section{MATERIALS AND METHODS}

Inbred pregnant hooded rats were used. They were housed in a room maintained at $24^{\circ} \pm 1^{\circ}$. They had free access to rat chow pellets and tap water throughout the experiments.

The litters studied had always six to eight animals. Larger or smaller litters were discarded. One group of animals was treated daily during 5 days of pregnancy (from day 15 to day 19) by subcutaneous injection of a suspension of $16-\beta$-metilprednisone at a dose of $1.25 \mathrm{mg} / \mathrm{kg} / \mathrm{day}$. The rest of the animals were used as controls. Daily vaginal samples were obtained prior to and during pregnancy. The smears were processed by the Shorr method and examined qualitatively to determine the estrous cycle. The first day of pregnancy was defined as the first day in estrus with spermatozoids present and later followed by a prolonged diestrus and detectable fetuses.
Body weight was controlled daily. The litters were killed within the first $24 \mathrm{hr}$ of life (newborns), at 17 days, or at 45 days of age. The brain (cerebral hemispheres, including olfactory lobe) was rapidly dissected out from the meninges and larger blood vessels and weighed. The left halves of the brains were dried at $70^{\circ}$ to a constant weight. Water content was calculated from the difference between wet and dry weights. Proteins and lipids were determined in the right half of the brain.

Total proteins were assayed by the method of Lowry (9). Lipids were extracted from brain samples with chloroform/methanol $2: 1$, according to the method of Folch et al. (6). The extract was dissolved with ethanol and aliquots were taken to determine total lipids (including unsaturate, free, and esterified fatty acids) by a colorimetric determination based on a modification of Chabrot and Charonnats using the sulfophosphovanillic reaction (20), cholesterol (10), and phospholipids (by a colorimetric determination of inorganic phosphate, after previous mineralization) (2). Values for proteins are expressed as milligrams per $\mathrm{g}$ wet tissue. Lipids are expressed similarly. The Student $t$-test was used for statistical evaluation of the data.

\section{RESULTS}

\section{BODY WEIGHT}

The rats from mothers treated with $16-\beta$-metilprednisone showed a statistically significant decrement in body weight at 17 days (Table 1). No differences were found between treated and control animals, at birth nor at 45 days of life.

Body weight from birth to 45 days of life follows a logistic function, mathematically expressed by the equation:

$$
\begin{aligned}
y & =\frac{K}{1+e[(\beta-t) /(\alpha)]} \\
y \text { (controls) } & =\frac{216.76}{1+e[(35.39-t) /(10.43)]} \\
y(\text { treated }) & =\frac{214.90}{1+c[(36.80-t) /(10.81)]}
\end{aligned}
$$

where $\mathrm{y}=$ body weight, $\mathrm{t}=$ time, $\mathrm{K}=$ asymptotic value, $\beta=$ curve inflexion point, $\frac{1}{\alpha}=$ inverse of the body weight rate (body increment per time unit), $\alpha=$ body weight rate. From the analysis of these functions a slower rate of increase of body weight for the treated rats is evident $(1 / 10,81)$ with respect to controls $(1 / 10,43)$.

The asymptotic value, although slightly lower in the treated animals, is not much different from controls. The different values of $\beta$ point in both groups indicate the beginning of a period of decreased body weight gain in the treated animals. At about 45 days of life, body weight gain is similar in both the control and the treated animals.

Table 1. Body and brain weight of control and steroid-treated rats

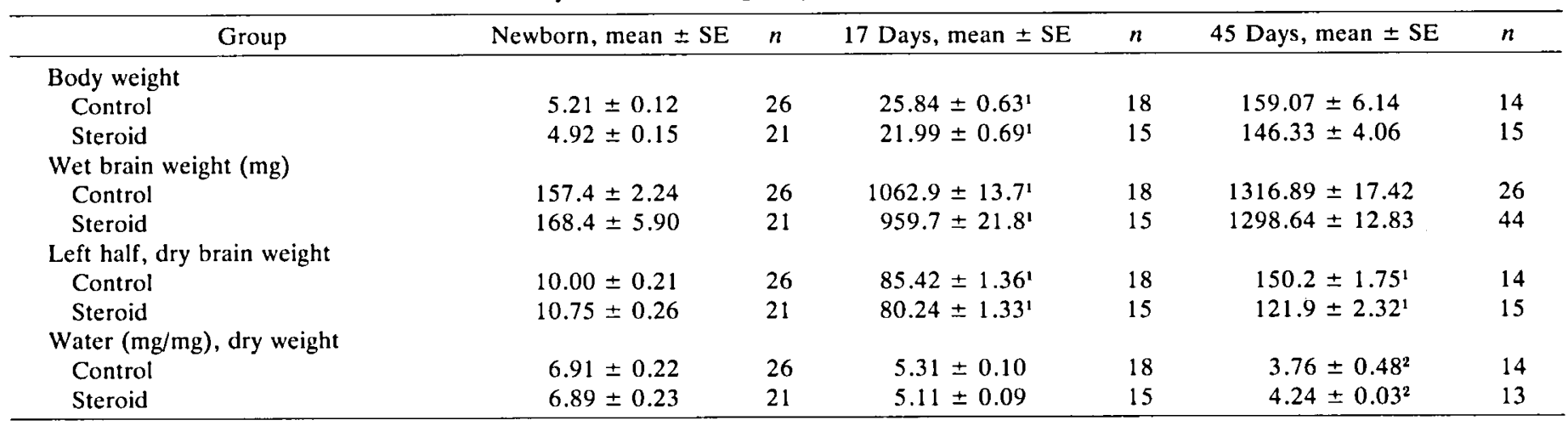

\footnotetext{
${ }^{1} P<0.01$.

${ }^{2} P<0.005$.
} 
Table 2. Brain lipids and protein content of control and steroid-treated rats

\begin{tabular}{|c|c|c|c|c|c|c|}
\hline Group & Newborn, mean $\pm S E$ & $n$ & 17 Days, mean $\pm S E$ & $n$ & 45 Days, mean $\pm S E$ & $n$ \\
\hline \multicolumn{7}{|l|}{ Protein $\mathrm{mg} / \mathrm{g}$ wet tissue } \\
\hline Control & $107 \pm 1.1^{1}$ & 17 & $130 \pm 3.8^{2}$ & 18 & $129 \pm 3.1$ & 14 \\
\hline Steroid & $85 \pm 2.8$ & 13 & $114 \pm 3.9^{2}$ & 15 & $139 \pm 4.0$ & 15 \\
\hline \multicolumn{7}{|c|}{ Total lipids, mg/g wet tissue } \\
\hline Control & & & $10.25 \pm 0.46$ & 19 & $18.21 \pm 0.32^{3}$ & 15 \\
\hline Steroid & & & $10.90 \pm 0.56$ & 20 & $13.01 \pm 0.67^{3}$ & 26 \\
\hline \multicolumn{7}{|c|}{ Cholesterol, $\mathrm{mg} / \mathrm{g}$ wet tissue } \\
\hline Control & & & $4.80 \pm 0.29$ & 16 & $7.62 \pm 0.30^{3}$ & 16 \\
\hline Steroid & & & $5.16 \pm 0.23$ & 20 & $5.41 \pm 0.35^{3}$ & 25 \\
\hline \multicolumn{7}{|c|}{ Phospholipids, $\mathrm{mg} / \mathrm{g}$ wet tissue } \\
\hline Control & & & $6.07 \pm 0.51^{3}$ & 17 & $8.93 \pm 0.82^{1}$ & 16 \\
\hline Steroid & & & $3.35 \pm 0.24^{3}$ & 12 & $5.85 \pm 0.48^{1}$ & 24 \\
\hline
\end{tabular}

\footnotetext{
${ }^{1} P<0.01$.

$2 P<0.05$.

${ }^{3} P<0.005$.
}

\section{WET BRAIN WEIGHT}

The values of treated animals were statistically lower than those of controls at 17 days of life.

\section{DRY BRAIN WEIGHT}

At 17 and 45 days of age treated animals showed a significantly decreased dry weight.

\section{WATER CONTENT PER MG DRY BRAIN WEIGHT}

At 45 days a significant increment of brain water was evident as compared with untreated animals (Table 1). No differences in this parameter were found in the newborn or in the 17-day-old animals with respect to their controls.

\section{BRAIN PROTEINS}

Newborn and 17-day-old rats treated with $16-\beta$-metilprednisone showed a remarkable decrease in brain proteins, as determined from wet tissue. This difference disappears at 45 days of life (Table 2).

\section{BRAIN LIPIDS}

A significant decrement of brain "total" lipids, cholesterol, and phospholipids became evident at 45 days in the treated animals (Table 2). Seventeen-day-old animals treated with the steroid had a decreased content of phospholipids but no differences were found in total lipids or in cholesterol (Table 2) when compared with their respective control groups. No differences between sexes were found in any of the parameters that were studied.

\section{DISCUSSION}

In the present work, 16- $\beta$-metilprednisone was administered to pregnant rats in the last week of pregnancy. The cerebral development was studied in newborn, in 17-day-old, and in 45day-old litters. These times of death were selected because they represent critical periods in the biochemical development of the brain; it is known that in the newborn and up to 10 days of age there is deposition of proteins and small deposition of lipids in the brain, and from this time up to 40 days of life there is great deposition of lipids and hence active myelination. This lipid increment occurs concomitantly with a decrease in the amount of water (18).

Changes in body and cerebral weights and the decreased protein content of the latter would be in part due to the known catabolic effect of glucocorticoids on protein metabolism. This would be supported by the fact that during the last week of pregnancy there is an important cellular division in the rat tetal brain, and by the known inhibitory effect of glucocorticoids on brain cells which might be associated with a decreased cellular number (3).

At about puberty the brain protein deficit disappeared in rats whose mother received prednisone treatment, indicating that recovery, although slow, occurs in this parameter.

The decreased dry brain weight observed in this work may reflect the decreased content of proteins and lipids (Tables 1 and 2 ). In agreement with the results of Vernadakis and Woodbury (18), we found that brain water, expressed as milligrams per mg dry weight, decreased in newborn and 17-day-old rats from the control as well as from the relative treated sample groups in the course of development (Table 1). The increment observed in 45day-old treated rats is probably related to the deficient lipid deposition process. In the present study brain total lipids, cholesterol, and phospholipid concentration are decreased at 45 days in the treated rats. It is known that brain lipids, mainly cholesterol and phospholipids, are components of the myelin sheath (4). Cholesterol may be considered a satisfactory index (or estimation) of lipid deposition; it is involved in myelination because of its accumulation in the free form in the myelin sheath and because of its possible role on fatty acid transport (8). Phospholipids, and most important among them, sphingomyelin, are also a component of myelin sheath in various mammalian species; phospholipid concentration increases with cerebral development (13). According to the present results it may be suggested that prenatal administration of $16-\beta$-metilprednisone decreased postnatal deposit rate of lipids and hence, delayed myelination of the brain.

In previous works (5) it has been reported that the protein matrix seems to be a limiting factor in the myelination process. Antibodies to brain proteins can inhibit myelination in vitro, and probably proteins may serve to cement together the membranes at the myelin sheath.

The decreased brain lipid deposition observed in the animals whose mothers received prednisone may be caused by a deficient protein matrix at the beginning of the myelination process.

\section{REFERENCES AND NOTES}

1. Adler, B.: Biología del desarrollo y malformaciones congénitas, p. 119 , (El Ateneo, Buenos Aires, 1974)

2. Beginski, E. S., Foa, P. P., and Zak, B.: Microdetermination of inorganic phosphate, phospholipids and total phosphate in biological materials. Clin. Chem., 13/4: 326 (1967).

3. Balázs, R., and Cotterrel, M.: Effect of hormonal state on cell number and functional maturation of the brain. Nature, 236: 348 (1972).

4. Corominas Vilardell, A.: Los lípidos: Laboratorio y Clínica, Ed. 1 (S. A. Toray, Barcelona, 1973).

5. Davison, A. N.: Biosynthesis of the myelin sheath: Lipids, malnutrition and 
the developing brain. A Ciba Foundation Symposium (Associated Scientific Publishers, Amsterdam, 1972).

6. Folch, J., Lees, M., and Scoane Stanley, G. H.: A simple method for the isolation and purification of total lipids from animal tissues. J. Biol. Chem., 226: 497 (1957).

7. Jurand, A.: The effect of hydrocortisone acetate on the development of mouse embryos. J. Embryol. Exp. Morphol., 20: 355 (1968).

8. Lovern, J. A.: The Chemistry of Lipids of Biologic Significance. (John Wiley and Sons., Inc., New York, 1955).

9. Lowry, O. H., Rosebrough, N. J., Farr, A. L., and Randall, R. J.: Protein measurements with the Folin phenol reagent. J. Biol. Chem., 193: 265 (1951).

10. Martinek, R. G.: Evaluation of a modification of the Zak-Kiliani reaction for determination of the serum cholesterol. Clin. Chem., 11(4): 495 (1965)

11. Moscona, M. H., and Karnosky, D. A.: Cortisone induced modifications in the development of the chick embryo. Endocrinology, 66: 533 (1960.

12. Oppenheimer, E.: Lesions in the adrenals of an infant following maternal corticosteroid therapy. Bull. Johns Hopkins Hosp., 114: 146 (1964).

13. Prensky, A. L., Mosis, A., Fishman, M., Tumblesen, M. E., and Daftari, B.: The lipid composition of the cerebral hemisphere of the miniature pig (sus scrofa), during development. Comp. Biochem. Physiol., 39: B 725 (1971)

14. Sames, G. L., and Leatham, J.: Influence of desoxycorticosterone and cortisone acetate on body weight of chick embryos. Proc. Soc. Exp. Biol. Med., 78: 231 (1951).

Copyright (1) 1977 International Pediatric Research Foundation, Inc.
15. Sato, H.: Effect of adrenocroticoids during pregnancy. Lancet, Vol. 11, 7319: 1235 (1963)

16. Shorr, E.: A new technique for staining vaginal smears: A single differential stain. Science, 94: 545 (1941)

17. Timiras, P. S., Vernadakis, A., and Sherwood, N.: In: N. S. Assali: Biology of Gestation, Vol. 2, p. 261 (Academic Press, New York, 1968).

18. Vernadakis, A., and Woodbury, D. M.: Electrolyte and aminoacid changes in rat brain during maturation. Amer. J. Physiol., 203: 748 (1962).

19. Yackel, D. B., Dempers, R. D., and McConahey, W. M.: Adrenocorticosteroid therapy in pregnancy. Amer. J. Obstet. Gynecol., 96: 985 (1966).

20. Zoliner, N., and Kirsch, K.: Uber die quantitative Bestimmung von lipoiden (Mikro-méthode) mittel der vielen naturlichen lipoiden (allen bekanten plasmalipoiden). Z. Ges. Exp. Med., 135: 545 (1962).

21. The authors are indebted to Dr. E. A. Pedernera for helpful discussion; to Mr. N. G. Amar for skillful technical assistance; to Miss M. Wagener for cooperation in some laboratory works, and to Dr. Roberto A. Prado-Alcalá for reviewing the manuscript. Statistical analysis was performed by Miss B. M. Pérez.

22. Reagents were kindly supplied by Wiener Laboratories.

23. Requests for reprints should be addressed to: M. C. Romano, M.D., Depart. de Fisiologia, Facultad de Medicine, Apdo. Postal 70250, Mexico 20, D. F. (U. N. A. M.)

24. Received for publication February 17, 1977

25. Accepted for publication March 2, 1977.

\title{
The Activity of Galactose-1-phosphate Uridyltransferase and Galactokinase in Human Fetal Organs
}

\author{
Y. S. SHIN-BUEHRING, T. BEIER, A. TAN, M. OSANG, AND J. SCHAUB ${ }^{(35)}$ \\ Children's Hospital, University of Munich, Munich, West Germany
}

\section{Summary}

The activity of galactose-1-phosphate uridyltransferase (transferase) and galactokinase in several organs from human fetuses 7-28 weeks old was measured by using radioactive substrates and column chromatography for product identification. The specific activity of transferase and galactokinase increased with gestational age and reached, at the 28th week, a maximal level of 30.0 and $7.9 \mathrm{nmol} / \mathrm{min} / \mathrm{mg}$ protein (units) in liver, 4.7 and 2.5 units in kidney, 6.0 and 4.0 units in lung, 6.7 and 2.9 units in spleen, 5.2 and 2.6 units in cardiac muscle, and 4.0 and 1.4 units in skeletal muscle, respectively. The activity in brain, on the other hand, remained quite constant with 1.2 units in the case of transferase and 0.5 units in the case of galactokinase during this period. The activities of both enzymes in the liver of children were slightly lower than the highest fetal level during the period of pregnancy studied. Galactokinase activity in fetal erythrocytes was approximately 4 times higher and the transferase activity approximately $30 \%$ higher than in adults. The $K_{m}$ value of fetal liver transferase for galactose-1-phosphate was found to be $0.330-0.357 \mathrm{mM}$ and that of galactokinase for galactose, $0.265-0.277 \mathrm{mM}$.

\section{Speculation}

It is postulated that the regulation of fetal galactokinase and transferase in brain is different from that in other organs with respect to the inducibility and development of these enzymes since the specific activities remained constant during a 5-month period of pregnancy in brain, in contrast to other organs. In view of the observation that the liver of a galactosemic child contained an uridyltransferase with extremely low binding affinity for galactose-1-phosphate, one of the causes for classic galactosemia may be altered binding sites rather than the complete absence of this enzyme.

Galactokinase (EC. 2.7.1.6) deficiency is an inborn error of galactose metabolism accompanied with galactosemia and galactosuria, which are caused by the inability to phosphorylate galactose to galactose-1-phosphate $(8,9)$. Another disorder of galactose metabolism known as classic galactosemia is characterized by the virtual absence of the galactose-1-phosphate uridyltransferase (EC. 2.7.7.12) which catalyzes the reaction galactose-1phosphate + UDP-glucose = glucose-1-phosphate + UDP-galactose. These enzymes have been observed in human erythrocytes $(12,14,24)$, leukocytes $(5,20)$, and in human liver $(2$, 25 ), and the defect of the enzymes in some of these tissues or cultured fibroblasts was found in galactosemic and galactokinase-deficient patients. The prenatal diagnosis of these genetic maladies can be accomplished by measuring the enzyme activity in cultured amnion cells $(6,23)$. 